\title{
Cinema e infância: produção cultural para crianças aparentemente desencantadas
}

Sueli Soares dos Santos Batista ${ }^{1}$

\begin{abstract}
Resumo: O artigo problematiza se apenas o estudo da concepção clássica de infância, principalmente o pensamento de Rousseau, pode iluminar os problemas relativos à educação das crianças no mundo contemporâneo. Parte-se da hipótese de que a infância é um conceito que pode ser analisado na perspectiva do que Adorno e Benjamin chamaram de história natural, em que mito, história e racionalidade estão imbricados. Analisamse aspectos de obras cinematográficas sinalizadoras de novas formas de encantamento e permanência dos mitos em torno da infância e da racionalidade e também de outras possibilidades para a relação entre homem e natureza, entre mito e história.
\end{abstract}

Palavras-chave: filosofia da infância, educação e cultura, teoria crítica.

Abstract: This article analyses if only the study of the classic conception of childhood, especially Rosseau's thinking, might illuminate the problems related to education of children in the contemporary world. It starts off from the hypothesis that childhood is a concept which can be analyzed under the perspective of what Adorno and Benjamin called natural history, in which myth, history and rationality are imbricated. This paper also discusses cinematographical works that signalize new forms of enchantment and endurance of the myths towards childhood and rationality, as well as other possibilities for the relation between human and nature, between myth and history.

Keywords: philosophy about childhood, education and culture, critical theory. 
Penso que o elemento de reconciliação está por toda parte onde o mundo se apresenta de forma mais aparente possível: em que a promessa de reconciliação vem dada da forma mais perfeita, ali onde o mundo, ao mesmo tempo, está mais fortemente amuralhado frente a todo sentido (ADORNO, 1991, p. 133).

Zadorosny (2005), inspirada nas reflexões de Chauí, procura um retorno aos princípios educacionais clássicos modernos, considerando que apenas o estudo da concepção tradicional de infância, principalmente o pensamento de Rousseau, pode iluminar os problemas relativos à educação das crianças (p. 391) Contra a tirania do novo e da mudança, propõe-se o resgate do ideal clássico de infância. O problema é que nem sempre esse ideal nos permite enxergar as condições objetivas em que as crianças atuais se desenvolvem. Contra o simulacro da pós-modernidade, não basta polarizarmos conceitos e ações falsas ou verdadeiras, representantes da aparência ou da realidade. Precisamos encontrar o conteúdo de verdade presente no véu ideológico- que é uma aparência socialmente necessária. Giacóia Jr. (2005), analisando fragmento de texto de Nietzsche publicado postumamente, conclui que

a mentira, o disfarce, a aparência não apenas não são o contrário absoluto da identidade, da verdade, da realidade e do ser, como constituem justamente as condições necessárias para a produção de efeitos de realidade e verdade no campo da moral e da política (p. 106).

Se o falso e o simulacro têm algo a dizer, optamos por uma crítica imanente ao conceito de infância no mundo contemporâneo, o que não significa descartar discussões que se mostrem vigorosas, independentemente do tempo e do espaço. A crítica imanente, no sentido dado por Adorno a essa expressão, não espera um despertar teleologicamente determinado para a desreificação, mas deposita na interpretação filosófica (profundamente empírica) do momento presente a possibilidade de "desencantamento" da história e da razão.

A infância, objeto de debate daqueles que afirmam seu desaparecimento ou permanência, é um conceito a ser analisado na perspectiva do que Adorno e Benjamin chamaram de história natural. Concordamos com Buck-Morss (1981, 
p. 134) quando afirma que a Dialética do esclarecimento foi a continuidade dada à tarefa iniciada por Adorno nos anos 30. Nos textos $A$ atualidade da filosofia e $A$ ideia de uma história natural, de 1931 (1991, 1991a, respectivamente), Adorno já apresenta elementos importantes do que mais tarde se configurará como uma dialética do esclarecimento. É a partir dessa perspectiva que, neste trabalho, procura-se analisar a recente produção cultural cinematográfica consumida, principalmente, por crianças que já não se enquadram no conceito tradicional e clássico de infância devido às condições objetivas da sociedade contemporânea. Essas crianças, nativos digitais, seriam menos infantis e ingênuas e menos sujeitas a influências do que os adultos estavam acostumados a imaginar.

A infância encantada, embalada pelos contos de fadas e pelas fábulas em que (quase sempre) o bem, o belo e o verdadeiro vencem, de alguma forma, esteve sob as suspeitas daqueles que tentaram resgatar a experiência frente às convencionalidades e o verniz civilizatório.

Rousseau, no Emílio, trabalha por esse desencantamento quando ironiza as fábulas de La Fontaine. Sua análise lógica é a base de uma defesa da autonomia moral, uma afirmação do mundo da infância que deve se desenvolver em direção à liberdade do adulto. A face iluminista de Rousseau, nesse episódio, mostra-se claramente:

\footnotetext{
Emílio nunca aprenderá nada de cor, nem mesmo fábulas, nem mesmo as de La Fontaine, pior ingênuas e encantadoras que sejam, porque as palavras das fábulas não são mais fábulas do que as palavras da história não são história. Como nos podemos cegar a ponto de encarar as fábulas como a moral das crianças, sem pensar que o apólogo, em as divertindo, as engana; que, seduzidas pela mentira, elas deixam escapar a verdade e que o que fazemos para tornar-lhes a instrução agradável as impede de dela aproveitar? As fábulas podem instruir os homens; mas é preciso dizer a verdade nua às crianças: desde que se cubra com um véu, elas não mais se preocupam em tirá-lo (1995, p. 104).
}

Rousseau analisa as fábulas de La Fontaine, especialmente $O$ corvo e a raposa, considerando-a ironicamente uma obra-prima incompreensível, pelo menos no seu objetivo primeiro como "moral das crianças". Rousseau 
posiciona as fábulas radicalmente do lado da mentira, do engano, da ilusão, da diversão e da sedução, em oposição à verdade própria da instrução. Rousseau, retoricamente, censura os criadores e os contadores de fábulas: "É assim que exercitais vosso aluno no espírito da crítica judiciosa que não se deixa impressionar senão com razão e sabe discernir a verdade da mentira nas narrativas dos outros? (ROUSSEAU, 1995, p. 106).

Assim é que Rousseau esforça-se por desencantar toda a narrativa de O corvo e a raposa, destacando os absurdos das imagens criadas, distantes do mundo natural, e as sutilezas que atingem o objetivo contrário: em vez de moderação, humanidade e justiça, testemunham licença, adulação, desumanidade, injustiça e sátira.

Mas, de alguma forma, as crianças se identificam com as fábulas? Rousseau reconhece que sim e vê nisso mais um argumento contra elas:

\footnotetext{
Observai as crianças aprendendo suas fábulas e vereis que, quando em condições de aplicá-las, elas o fazem quase sempre ao contrário da intenção do autor e que, ao invés de atentarem para o defeito de que thes querem curar ou prevenir, elas se inclinam para o vício mediante o qual se tira proveito dos defeitos dos outros. Na fábula precedente, as crianças zombam do corvo, mas se afeiçoam todas à raposa, na fábula seguinte, pensai dar-Ihes a cigarra como exemplo; nada é a formiga que escolherão (p. 108).
}

A identificação das crianças, contrariando a intenção inicial do autor, ou mesmo do preceptor, é atribuída a Rousseau ao amor próprio: ninguém gosta de se humilhar. Assim é que a criança se identifica com a lebre rápida e esperta, e não com a tartaruga lenta e desengonçada, com a alegre e divertida cigarra, e não com a formiga rigorosa e fatigada. Se a criança, nesse aspecto, confirma a hipótese de Rousseau quanto ao amor próprio, também contraria o princípio da piedade na natureza humana:

Em todas as fábulas em que o leão é um dos personagens, como é de costume o mais brilhante, a criança não deixa de se fazer de leão; e quando preside alguma partilha, bem instruída por seu 
modelo, tem o cuidado de tudo açambarcar. Quando o mosquito domina o leão, a coisa muda; a criança não é mais então o leão, e sim o mosquito. Aprende a matar um dia a golpes de ferrão os que não ousaria atacar de frente (p. 109).

Para Rousseau, as fábulas estão repletas de conceitos que se contradizem. É preciso uma leitura atenta e racional, ou seja, adulta, para que não se escolha o lado errado, para que a criança "ao invés em vez de se corrigir com a vítima, não se forme com o malandro" (1995, p. 109).

Como temos observado, essas contradições anatematizadas por Rousseau são próprias da formação individual e coletiva, à medida que a autoconservação é a lei natural de todos os viventes. Confirma-se, como história natural, o princípio hobbessiano, que Rousseau seria obrigado a reconhecer.

Rousseau demonstra indignação perante um elemento fundamental das fábulas: os animais falam: "Então as raposas falam? E falam a mesma língua que os corvos? Prudente preceptor, toma cuidado; pesa bem tua resposta antes de dá-la; tem mais importância do que imaginas" (p. 106).

Rousseau não se estende muito sobre esse confabular entre corvo e raposa, apenas lançando a suspeita ao preceptor de que ali haveria muito mais importância do que se vê inicialmente. Se as crianças não compreendem a lógica, a linguagem e a moral das fábulas, por que, ainda assim, identificam-se com seus personagens? Infantes e animais não falam. Têm uma linguagem não articulada e não dominam um discurso. Não estaria aí a base da identificação?

Agamben define fábula como o lugar "em que, mediante a inversão das categorias boca fechada/ boca aberta, pura língua/infância, o homem e a natureza trocam seus papéis antes de reencontrarem a parte que lhes cabe na história" (2005, p. 78).

O autor, refletindo sobre as fábulas, a partir do conceito benjaminiano de história natural, considera que as fábulas contêm a verdade da infância como dimensão original do homem (p. 77). Ou seja, antes de opor verdade e mentira 
numa análise discursiva das fábulas, Agamben procura o conteúdo de verdade das fábulas na existência de seres historicamente silenciados por um humanismo que relega tanto a infância quanto a natureza ao silêncio.

Ela representa o recomeço a partir de uma aura de pureza e de inocência e remete ao mito de uma origem, à presentificação de um ideal não consumado, à uma mensagem da qual é portadora. Perante sua majestade, o bebê, o comum que se curvem embevecidos na contemplação do que gostariam de ser. O nascimento de uma criança é associado à luz e à iluminação. A figura do presépio é exemplar nesse sentido. Para Agamben, o presépio, como imagem histórica, "mostra precisamente o mundo da fábula no instante em que desperta do encanto para entrar na história" (2005, p. 153). Perante o Deus menino ou o homem deificado, os animais e os homens comuns silenciam.

O animal que fala é aquele que deixa de ser apenas natureza para entrar na história, ou seja, constitui-se como sujeito histórico. Esse não é um processo contínuo e regular, mas descontínuo e contraditório. Agamben questiona se a natureza está novamente para entrar na fábula, pedindo novamente palavra à história à medida que "o homem, enfeitiçado precisamente por uma história que volta a assumir para ele os traços obscuros do destino, emudece no encanto" (p. 158).

Um a fábula moderna de muito sucesso entre adultos e crianças é $A$ era do gelo. Todas as edições do filme (a primeira delas foi lançada em 2002) acontecem num período de catástrofes para o planeta Terra. Só animais falam; seres humanos adultos, meros coadjuvantes, balbuciam. A única criança de toda a história tem suas primeiras experiências de sobrevivência com os animais. Só depois que aprende a andar é que vai ter os primeiros contatos efetivos com seus pais.

As fábulas de La Fontaine ainda não foram completamente superadas, e as fábulas modernas surgem fazendo uma releitura dessa voz da natureza que não é apenas língua, mas se apropria do mundo, discursando como o humano 
adulto. As contradições lógicas, esteticamente expressadas pela computação gráfica, não afastam ninguém das fábulas em suas versões modernas. Pelo contrário, as fábulas estão na ordem do dia, mostrando que os homens emudecem, sim, perante uma história que se apresenta como natureza; os animais e as forças naturais falam, quase exigindo uma mudança no curso histórico de depredação da natureza; os homens e os animais falam, até conversam, indicando talvez novos caminhos.

Depois de assistir ao desencantamento de bichos-papões, lobisomens e Papai Noel, a ideia de infância é a última a ser liquidada. Os seres que povoavam a imaginação infantil estão órfãos: não há mais crianças que possam adotá-los. O sucesso de filmes como Shrek, que já conta com quatro edições, é sintomático disso. Fadas, príncipes e princesas são banidos ou ridicularizados, exaltando-se em seu lugar ogros comedores de ratos, que soltam seus gases no pântano mais próximo.

Para explicar o sucesso do desenho em computação gráfica, comentaristas apresentam Shrek, surgido inicialmente em 2001, como uma exceção notável entre os ogros: não possui cérebro reduzido, não demonstra insanidade e incompetência. Mas é possível afirmar que é justamente a monstruosidade (tanto de Shrek quanto de sua amada, Fiona) que atrai o suposto público infantil, cansado das versões açucaradas dos contos de fadas.

Embora Shrek seja um conto de fadas às avessas, é possível que as crianças o entendam mesmo que não conheçam integralmente as inúmeras citações feitas. O fato é que o que foi banido reaparece. O ogro que vivia na periferia do reino, ainda que com sacrifício, vê-se como possível ocupante do trono. A monstruosidade tradicionalmente banida também habita, sigilosamente, a torre do castelo, na alma da princesa que sofre de uma maldição: tornar-se ogro sempre que o sol se põe, até que, pelo beijo do amor verdadeiro, escolhe assumir definitivamente a forma de ogro.

Os ogros povoam também os jogos eletrônicos. Em sites especializados, é possível verificar as descrições desses monstros (bem menos temidos): 
são enormes e estúpidos; osão avessos a banhos; exalam odores horríveis; não constroem cidades; são eremitas; vivem sempre sós, associando-se apenas para reprodução; e abandonam suas crianças assim que nascem. Mesmo o apaixonado e adaptável Shrek, quando sabe que terá filhos, sofre de pesadelos e alucinações, talvez ensaiando uma recaída na sua "natureza" de ogro.

Volmer e Ramos (2007), analisando a recepção das crianças em relação ao filme, concluíram que seus personagens permitem discutir os valores emergentes na sociedade, revelando o quanto somos "produto" do meio em que estamos inseridos.

Queremos destacar, em Shrek, a emergência de uma crítica à padronização, no sentido de resgatar a natureza não conformada, seja na criança, seja no adulto. Aquele que está fora da cidade, reconhecido como ameaça, transforma-se, com algumas concessões mútuas, em participante pleno da sociedade. Lembremos que Shrek, ao conquistar a cidadania, traz consigo todos os personagens dos contos de fada. Sua atuação começa com o exílio imposto a todos eles por lorde Farkward, um adulto com tamanho de criança. Essa criança adultizada (ou esse adulto infantilizado) é o que desencadeia a aproximação entre Shrek e Fiona, que causará o fracasso do esperado príncipe encantado. Lorde Farkward não representaria essa criança que se distancia cada vez mais dos mitos que a fizeram acreditar durante longo tempo em padrões que se tornam atualmente inócuos? Shrek é o príncipe desencantado porque a infância para qual se dirige também se desencantou e se identifica mais com aquele que, embora banido inicialmente, traz à cena a natureza não totalmente dominada.

A deformidade e a monstruosidade sublimadas, via de regra, em diversas releituras dos contos de fadas, como A Bela e a Fera, ganham novas abordagens. Figuras estranhas e até repulsivas povoam outra narrativa contemporânea: Monstros S.A, de 2001. Dependentes da energia resultante dos gritos de horror das crianças, a sobrevivência das mais bizarras criaturas está ameaçada, porque as crianças já não se assustam tanto com a feiúra deles. 
As monstruosas personagens da história, na verdade, têm horror às crianças, porque temem ser contaminadas por elas. Toda a narrativa é para mostrar que monstros e crianças podem se dar muito bem e se divertirem juntos. A história de Grunch, lançada em 2000, possui a mesma ideia de uma conciliação entre um mundo normal e civilizado que rejeita estranhos, esquisitos, banidos e monstruosos que não se enquadram nos padrões das sociedades humanas, mas acaba aceitando-os e se associando a eles. O monstro Grunch "rouba" o Natal no mundo dos "quem", criaturas bem diminutas, mas não o suficiente para que não sejam consumistas vorazes. Apesar de sua resistência, o monstro Grunch acaba aceitando o Natal, incorporando-se à comunidade que antes o humilhara e o banira, mas dá uma lição: o que importa é o espírito do Natal, e não as mercadorias que consumimos em nome das festas natalinas.

Ogros e monstros podem continuar feios e estranhos. São aceitos pela comunidade humana ao mostrarem que a humanidade tem a sua monstruosidade oculta em padrões de comportamento e de beleza que, se olhados bem de perto, são também bem feios e monstruosos. Ao contrário dos sapos e das feras que viram príncipes sob o efeito de um beijo que põe fim a um encantamento, nessas histórias, os príncipes ou os amigos podem continuar com sua aparência pouco agradável. Nessas histórias admiradas por adultos e crianças, essas criaturas banidas contribuem com a sua monstruosidade, sob a qual escondem virtudes. Por sua vez, os adultos que estão sob a civilidade, aos poucos, revelam em suas atitudes o que nela está ocultado. As crianças, nessas histórias, são as que desencadeiam esse processo de descoberta, mostrando para monstros e humanos como estão, na verdade, próximos uns dos outros.

Mesmo estimulando uma maior tolerância com a animalidade e a monstruosidade, essas histórias, antigas e atuais, terminam com uma conciliação entre a humanidade e a natureza não totalmente conformada que também habita nos seres humanos. O encantamento permanece de alguma forma; e todos, humanos, animais e monstros, conseguem apaziguar o medo que nutrem uns pelos outros. 


\section{Referências}

ADORNO, T. W. "La actualidad de la filosofía". In: La actualidad de la filosofía. Tradução de Antonio Aguilera. México: Ediciones Paidós, 1991.

"La idea de uma historia natural". In: La actualidad de la filosofia. (trad. Antonio Aguilera). Tradução de Antonio Aguilera. México: Ediciones Paidós, 1991a.

AGAMBEN, G. Infância e história. Belo Horizonte: UFMG, 2005.

BUCK-MORSS, S. Origen de la dialética negativa: Theodor Adorno, Walter Benjamin y el Instituto de Frankfurt. Tradução de Nora Rabotnikok Maskivker. México: Siglo 21, 1981. GIACÓIA JR., O. "A mentira e as figuras da ilusão". In: MARQUES, J. O. A. (Org.). Verdades e mentiras. 30 Ensaios em torno de Jean-Jacques Rousseau. Ijuí: Unijuí, 2005. ROUSSEAU, J-J. Emílio ou Da Educação. Tradução de Sergio Milliet. Rio de Janeiro: Bertrand Brasil, 1995.

VOLMER, L.; RAMOS, F. B. "Infância, cinema e leitura: um tripé viável". In: Revista Ciências \& Cognição. Rio de Janeiro, ano 4, v. 12, 2007. Disponível em: <http://www. cienciasecognicao.org >. Acesso em: 20 mai. 2009.

ZADOROSNY, K. J. A. S. "Rousseau e o moderno sentimento de infância: um legado a ser recuperado". In: 'MARQUES, J. O. A. (Org.). Verdades e mentiras. 30 ensaios em torno de Jean-Jacques Rousseau. Ijuí: Editora Unijuí, 200.

1 Doutora em psicologia do desenvolvimento (USP) e pós-doutoranda em história e filosofia da educação (Unicamp). Email: prof.sueli@fatecjd.edu.br. 